\title{
Intensive case management was not more cost effective than standard case management for severe psychosis
}

UK700 Group. Cost-effectiveness of intensive v standard case management for severe psychotic illness. UK700 case management trial. Br J Psychiatry 2000 Jun;176:537-43.

\section{QUESTION: In patients with severe psychosis, is intensive case management more cost effective than standard case management?}

Design

Cost effectiveness analysis (from the perspective of all service providing sectors) of a randomised (allocation concealed*), unblinded*, controlled trial with 24 months of follow up.

\section{Setting}

4 inner city hospitals in the UK (3 in London, 1 in Manchester).

\section{Patients}

708 patients who were 18-65 years of age \{mean age $38 \mathrm{y}$, $57 \%$ men $\} \nmid$ and had had a psychotic illness for $\geqslant 2$ years with $\geqslant 2$ hospital admissions. Exclusion criteria were organic brain damage or primary diagnosis of substance abuse. $94 \%$ of patients were included in the economic analysis.

\section{Intervention}

Patients were allocated to intensive case management (ICM) $(\mathrm{n}=335)$ or standard case management (SCM) $(\mathrm{n}=332)$. The case load size was $10-15$ cases per case manager for intensive case management and 30-35 cases per case manager for standard case management.

\section{Main cost and outcome measures}

The main outcome was the number of days in hospital for psychiatric problems. Secondary outcomes were clinical status (Comprehensive Psychiatric Rating Scale), quality of life (Lancashire Quality of Life Profile), unmet needs (Camberwell Assessment of Need), social disability (WHO Disability Assessment Schedule), and patient satisfaction (self report questionnaire). Direct costs were assessed for the use of all hospital and community services in 1997-8 UK pounds sterling. Future costs were discounted at an annual rate of $6 \%$.

\section{Main results}

Sources of funding: UK Department of Health and NHS Research and Development Programme.

For correspondence: Ms S Byford, Centre for Health Economics,

University of York, Heslington, York YO10 5DD, UK. Fax $+44(0) 1904433644$.
Analysis was by intention to treat. Groups did not differ for the number of days in hospital (mean difference $0.4 \mathrm{~d}$, $95 \%$ CI -17.4 to 18.1) or any of the secondary outcomes. The total cost of case management per patient was higher for ICM than for SCM ( $\$ 3089 v £ 1259$; mean difference £1830, CI £1562 to £2098). ICM and SCM did not differ, however, in mean overall costs of care per patient (£24 553 v22 704, respectively; mean difference $£ 1849$, CI $-£ 1605$ to $£ 5304$ ).

\section{Conclusion}

In patients with severe psychosis, intensive case management was not more cost effective than standard case management.
*See glossary.

$\dagger$ Burns T, Creed F, Fahy T, et al, for the UK700 Group. Intensive versus standard case management for severe psychotic illness: a randomised trial. Lancet 1999;353:2185-9.

\section{COMMENTARY}

Outcome literature is unclear about costs of ICM. For example, when comparing assertive community treatment (ACT) with hospital based treatment, costs were higher by about $10 \%$ but were lower for indirect treatment (eg, social services and private medical providers), law enforcement, maintenance, and family burdens. ${ }^{1}$

British health authorities wanted to know if the North American ICM model, the ACT programme, would work in the UK. This was 1 major purpose of the UK700 trial. ${ }^{2}$ It failed to prove that ICM is more cost effective, but Holloway et al reminded us that hospital admission can be influenced by factors other than patients' needs; they considered that using hospital admission as an outcome measure for case management is questionable. ${ }^{3}$

The authors did a subgroup analysis on whether the severity of social functioning made a difference to the results. The absence of cost differences according to the severity of social functioning is puzzling because patient characteristics, not just the type of case management, determine cost effectiveness. ${ }^{4}$

Only a smaller proportion of difficult, unstable, frequently substance abusing patients need ICM, and such need can vary over time. In my opinion, the benefits and costs of ICM may have been better evaluated in a group of difficult patients. ICM and SCM should aim to serve different clients, and if possible, ICM and SCM should both be part of local psychiatric services to meet the different and evolving needs of severely mentally ill patients.

Raymond Tempier, MD, MSc, FRCPC Montreal General Hospital Montreal, Québec, Canada

1 Weisbrod BA, Test MA, Stein LI. Alternative to mental hospital treatment. II. Economic benefit-cost analysis. Arch Gen Psychiatry 1980;37:400-5.

2 Burns T. Methodological problems of schizophrenia trials in community settings. In: Guimón J, Sartorius N, editors. Manage or perish? The challenges of managed mental health care in Europe. New York: Kluwer Academic/Plenum Publishers, 1999:267-76.

3 Holloway F, Oliver N, Collins E, et al. Case management: a critical review of the outcome literature. European Psychiatry 1995;10:113-28.

4 Clark RE, Fox TS. A framework for evaluating the economic impact of case management. Hosp Community Psychiatry 1993;44:469-73 